\section{CVIA}

REVIEW ARTICLE

pISSN 2508-707X / eISSN 2508-7088 https://doi.org/10.22468/cvia.2017.00136 CVIA 2018;2(1):1-11

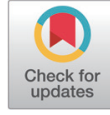

\title{
Role of Coronary CT Angiography in Coronary Revascularization
}

\author{
Jin Young Yoo', Jin-Ho Choi ${ }^{2}$, Jeong A Kim³, Eun Ju Chun ${ }^{4}$ \\ 'Department of Radiology, Chungbuk National University Hospital, Cheongju, Korea \\ ${ }^{2}$ Department of Internal Medicine, Samsung Medical Center, Sungkyunkwan University \\ School of Medicine, Seoul, Korea \\ ${ }^{3}$ Department of Radiology, Inje University Ilsan Paik Hospital, Goyang, Korea \\ ${ }^{4}$ Department of Radiology, Seoul National University Bundang Hospital, Seongnam, Korea
}

Received: September 2, 2017

Revised: November 9, 2017

Accepted: November 22, 2017

Corresponding author

Eun Ju Chun, MD, PhD

Department of Radiology,

Seoul National University

Bundang Hospital,

82 Gumi-ro 173beon-gil, Bundang-gu,

Seongnam 13620, Korea

Tel: 82-31-787-7618

Fax: 82-31-787-4011

E-mail: drejchun@hanmail.net

\begin{abstract}
Since the development of computed tomography (CT) technology over the last decade, coronary CT angiography (CCTA) has become a powerful non-invasive method for evaluating coronary artery disease. Recently, CT has been used to evaluate hemodynamic status beyond anatomy by current trials such as perfusion $\mathrm{CT}$, fractional flow reserve-CT, or transluminal attenuation gradient, which can help determine whether coronary revascularization occurs. Once revascularization is determined, CT can guide whether to use a stent or coronary artery bypass graft ( $C A B G)$ for the reperfusion method by evaluating the nature of the lesion. In addition, CCTA helps to better define the morphological features of the occluded chronic total occlusion segment such as the occlusion length and presence of calcifications or tortuosity in its course, which are established predictors of success. Finally, CT can assess the patency of a stent or CABG in patients who previously underwent revascularization. Therefore, this review article discusses the various roles of CCTA in coronary revascularization.
\end{abstract}

Key words CT angiography - Myocardial perfusion imaging · Myocardial fractional flow reserve $\cdot$ Percutaneous coronary intervention $\cdot$ Coronary artery bypass.

\section{INTRODUCTION}

With the remarkable development of the computed tomography (CT) technique, coronary CT angiography (CCTA) has become a routine and widely accepted modality for evaluation of patients with chest pain because it shows high diagnostic accuracy, especially in terms of its high negative predictive value (NPV) [1]. In addition, CCTA can be used to visualize atherosclerotic plaques in the vessel wall in contrast to "lumenography" performed by invasive coronary angiography (ICA). Therefore, the ability to interpret CCTA images beyond visualization of the coronary lumen and stenosis is of utmost importance because it enables therapeutic interventions stratified based on plaque characteristics [2]. In addition, recent trials for evaluation of the hemodynamic status such as myocardial CT perfusion (CTP), fractional flow reserve (FFR)-CT $\left(\mathrm{CT}_{\mathrm{FFR}}\right)$, and transluminal attenuation gradient (TAG) have been introduced [3-5]. Based on these current $\mathrm{CT}$ techniques which can provide both anatomy and functional information, cardiac CT may play an important

(a) This is an Open Access article distributed under the terms of the Creative Commons Attribution Non-Commercial License (http://creativecommons.org/licenses/bync/4.0) which permits unrestricted non-commercial use, distribution, and reproduction in any medium, provided the original work is properly cited. role in the determination of whether or not to perform coronary revascularization in patients with chest pain. Once revascularization has been determined, CT can guide whether to use a stent or coronary artery bypass graft (CABG) for the reperfusion method by evaluating lesion length, multiplicity, and complexity [6]. In cases of patients with chronic total occlusion (CTO), CT has a critical role in guiding treatment because it allows observation of the distal part beyond the occlusion, which cannot be seen by ICA [7]. Finally, CT has a potential role in the assessment of the patency of a stent or CABG in patients who previously underwent revascularization [8]. An understanding of the role of $\mathrm{CT}$ and keeping up to date with the evolving CT technology are both critical in coronary interventions.

\section{STEP 1. DECISION ON WHETHER TO TREAT WITH MEDICATION OR REVASCULARIZATION}

Determining the appropriate treatment strategy is very important for patients with chest pain. When deciding if myocardial revascularization should be performed, anatomical steno- 
sis as well as hemodynamic status should be considered (Fig. 1).

\section{Quantification of the degree of stenosis}

ICA is considered as the standard reference because it has a high spatial resolution of $0.3 \mathrm{~mm}$ and a temporal resolution of 6 msec [9]. On the other hand, the current CT equipment has a spatial resolution of $0.23 \mathrm{~mm}$ (Revolution CT, GE Healthcare, Waukesha, WI, USA) and temporal resolution of $66 \mathrm{msec}$ at 0.25 sec rotation (dual source, SOMATOM Force, Siemens Healthcare, Forchheim, Germany) with a high NPV and sensitivity more than $95 \%$; however, the positive predictive value (PPV) or specificity is less than $95 \%[10,11]$. Several studies and metaanalyses have shown that CCTA is reliable for ruling out significant coronary artery disease (CAD) in patients with stable and unstable angina syndromes and in patients with low to moderate likelihood of CAD [12,13]. However, the diagnostic accuracy of CCTA can be reduced by heavily calcified coronary arteries mainly due to the so-called blooming artifact, which leads to overestimation of the severity of atherosclerotic obstructions, thus higher coronary artery calcium score results which decreases the specificity by $35-45 \%$ [14].

\section{Plaque burden and characteristics}

The likelihood of plaque rupture has been known to be based on plaque composition. In ROMICAT I and II trials, high-risk plaques detected on CCTA predicted acute coronary syndromes independent of significant $\mathrm{CAD}$ and clinical risk assessment [2]. Several recent studies have reported low-attenuation, positive remodeling, the napkin-ring sign, and spotty calcifications as features of high-risk plaques [15,16] (Fig. 2). These rupture-prone plaques have been described histologically as thin cap fibroatheromas [17].

To identify low attenuated plaques (LAP), a region of interest (ROI) was set within each plaque to calculate the plaque density. On CT, lipid content correlates with lower CT attenuation values when compared with fibrotic tissue [18]. However, CT

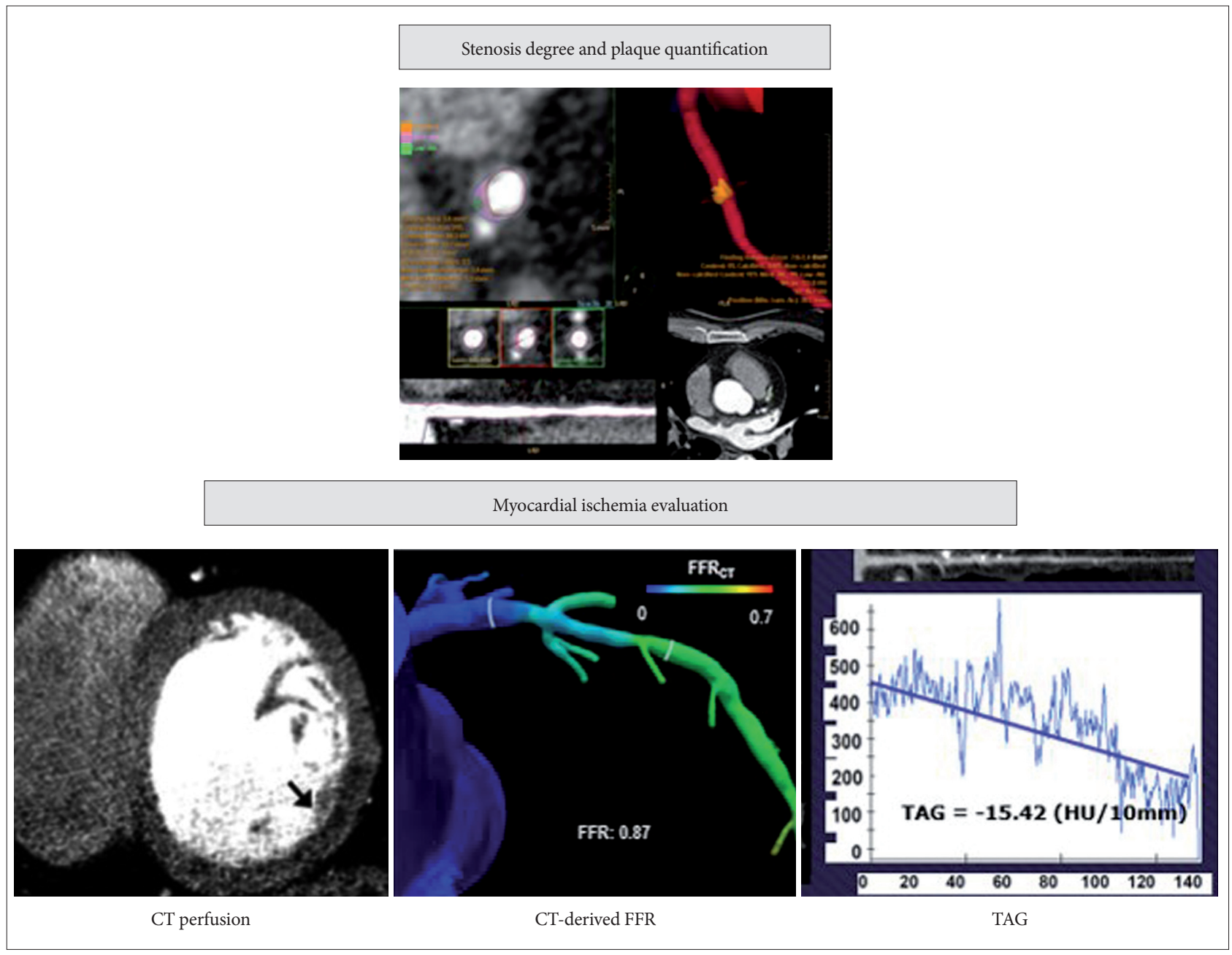

Fig. 1. Diagram of various CT modalities for determining whether to treat with medication or revascularization. Arrow in CT perfusion image indicates areas where myocardial perfusion is reduced. CT: computed tomography, FFR: fractional flow reserve, TAG: transluminal attenuation gradient. 
measurements of coronary plaques are influenced by many factors: the concentration of intraluminal iodinated contrast agent, plaque size, image noise, tube voltage, slice thickness, and reconstruction filter. Thus, reliable differentiation of the density between lipid-rich plaques and fibrous plaques is not yet feasible. Motoyama et al. [15] proposed 30 Hounsfield units (HU) as the cutoff point for the detection of lipid cores in intravascular ultrasound (IVUS) with a sensitivity of $91 \%$ and specificity of $100 \%$, although there is no description of the method used to identify LAPs. Otsuka et al. [19] defined a LAP when the mean value of at least 5 randomly selected points within each plaque was less than $30 \mathrm{HU}$. In an ex vivo study, the relative area (area $>25 \%$ ) of intraplaque pixels with $<60 \mathrm{HU}$ could accurately detect lipid-rich plaques with a sensitivity of $73 \%$ and specificity of $71 \%$ [20]. Until now, however, there are no consistent guidelines on how to measure LAPs or the appropriate cut-off
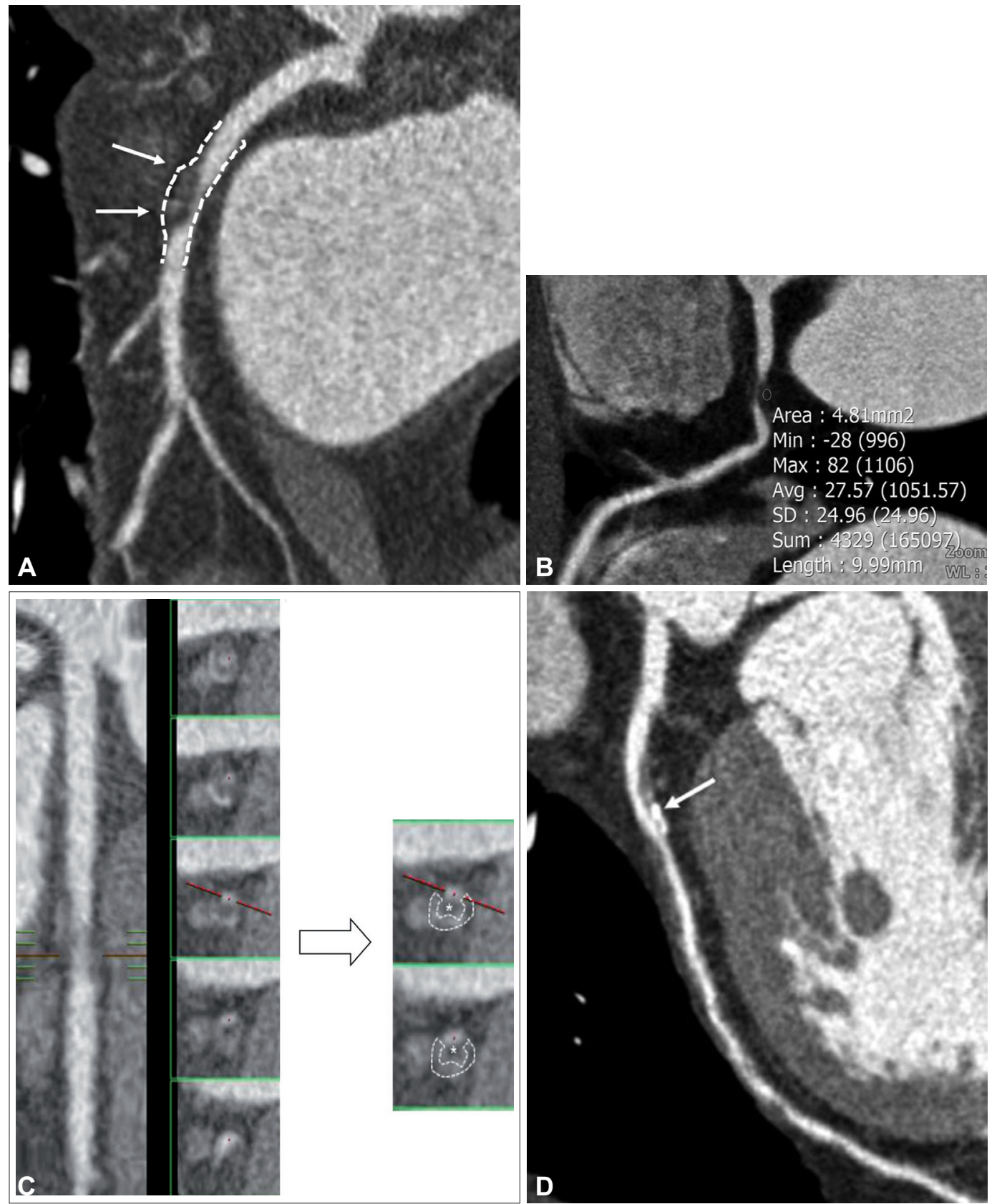

Fig. 2. Various high-risk plaques. (A) Positive remodeling (arrows): remodeling index determined for the outer vessel wall calculated by the vessel cross-sectional area at the site of maximal stenosis divided by the cross-sectional areas of the reference segments, threshold of 21.1. (B) Low attenuated plaque: average plaque attenuation of the selected region of interest was less than $30 \mathrm{HU}$. (C) Napkin-ring sign: plaque core with low attenuation (asterisk) surrounded by a rim-like area of higher attenuation (dotted line). (D) Spotty calcification (arrow): size $<3 \mathrm{~mm}$ with a computed tomography density of over $130 \mathrm{HU}$ within the plaque. HU: Hounsfield units. 
levels for their identification.

Rupture-prone plaques might not lead to significant luminal narrowing, owing to the effect of positive remodeling. Positive remodeling is the compensatory enlargement of the vessel wall that occurs at the site of an atherosclerotic lesion as the plaque size increases, resulting in preservation of the luminal area [21]. In histopathology, positive remodeling is associated with an abundance of macrophages and increased necrotic core [22]. CCTA can be used to measure the outer vessel wall as calculated by the vessel cross-sectional area at the site of maximal stenosis divided by the average of the cross-sectional areas of the proximal and distal reference segments. Usually, a remodeling index threshold of $\geq 1.1$ is defined as positive remodeling [2]. A napkin-ring sign is characterized by a plaque core with low computed tomography attenuation surrounded by a rim-like area of higher attenuation [16]. Therefore, there is no cut-off value for central low attenuation and peripheral higher attenuation, but the presence of rim-like high attenuation is defined as a relatively higher attenuation compared to an adjacent plaque and no greater than $130 \mathrm{HU}$. This sign was more frequent in thin cap fibroatheroma (TCFA) compared with non-TCFA plaques defined by optical coherence tomography [23]. Napkin-ring sign seems to be a specific feature of plaques with a large necrotic core, although its sensitivity is low [22]. Spotty calcification was defined as a plaque $<3 \mathrm{~mm}$ in size with a CT density of over 130 $\mathrm{HU}$ within the plaque [2]. According to the size of a spotty calcification, small (<1 mm) spotty calcifications have been strongly correlated with vulnerable plaque features based on virtual his- tology IVUS [24]. However, there is controversy on whether such calcifications reflect the vulnerability of a plaque in some studies [25].

\section{CT-based myocardial ischemic burden (CTP, CT $_{\mathrm{FFR}}$, and TAG)}

Although CCTA accurately assesses coronary plaques and stenosis, it is limited in evaluating the hemodynamic significance of coronary stenosis. Recently, however, three novel techniques have been demonstrated to accurately detect vessel-specific ischemia using the gold standard invasive FFR as a reference. Based on these modalities, the decision between treatment with medication and coronary revascularization can be done.

\section{CTP}

Using a pharmacologic agent such as adenosine, an acquisition image was obtained during the first pass of iodinated contrast from the arteries into the myocardium where hypoperfusion is represented by low attenuated areas. This requires both resting and stress scans, therefore additional administration of adenosine, iodinated contrast agent, and radiation exposure are required [26]. In particular, the excessive radiation dose is considered as one of the important limitations of CTP. However, the average radiation exposure from stress static CTP (6.5 $\mathrm{mSv})$, stress dynamic CTP (10.0 mSv), and rest/stress dual-energy CTP (5.6/7.1 mSv) are lower compared to SPECT (11.1 $\mathrm{mSv}$ ); furthermore, high-pitched spiral static CTP demonstrated the lowest radiation doses for stress and rest CTP $(0.93 \mathrm{mSv}$

Table 1. Diagnostic accuracy of CTP imaging

\begin{tabular}{|c|c|c|c|c|c|c|c|}
\hline Study & $\begin{array}{c}\text { Number of } \\
\text { patients/vessels }\end{array}$ & CT technique & Reference standard & Sensitivity (\%) & Specificity (\%) & PPV (\%) & NPV (\%) \\
\hline \multirow[t]{3}{*}{ Ko et al. [30] } & $42 / 86$ & CCTA & $\mathrm{FFR} \leq 0.80$ & 93 & 60 & 68 & 90 \\
\hline & & CTP & & 76 & 84 & 82 & 79 \\
\hline & & $\mathrm{CCTA}+\mathrm{CTP}$ & & 68 & 98 & 97 & 77 \\
\hline \multirow[t]{3}{*}{ Bettencourt et al. [31] } & $101 / 303$ & CCTA & $\mathrm{FFR} \leq 0.80$ & 95 & 67 & 48 & 97 \\
\hline & & CTP & & 55 & 95 & 78 & 87 \\
\hline & & $\mathrm{CCTA}+\mathrm{CTP}$ & & 71 & 90 & 68 & 91 \\
\hline \multirow[t]{3}{*}{ Greif et al. [34] } & $65 / 195$ & CCTA & $\mathrm{FFR} \leq 0.80$ & 98 & 54 & 37 & 99 \\
\hline & & CTP & & 95 & 74 & 49 & 98 \\
\hline & & CСТА+CTP & & 95 & 75 & 50 & 98 \\
\hline \multirow[t]{2}{*}{ Wong et al. [32] } & $75 / 127$ & CCTA & $\mathrm{FFR} \leq 0.80$ & 89 & 66 & 57 & 92 \\
\hline & & CCTA+CTP & & 76 & 89 & 78 & 88 \\
\hline \multirow[t]{3}{*}{ Choo et al. [33] } & $37 / 81$ & CCTA & $\mathrm{FFR} \leq 0.80$ & 93 & 83 & 75 & 96 \\
\hline & & CTP & & 93 & 90 & 84 & 96 \\
\hline & & ССТА+СТP & & 93 & 94 & 90 & 96 \\
\hline \multirow[t]{3}{*}{ Yang et al. [28] } & $75 / 210$ & CCTA & $\mathrm{FFR} \leq 0.80$ & 97 & 43 & 88 & 75 \\
\hline & & CTP & & 89 & 86 & 96 & 63 \\
\hline & & CСТА+CTP & & 86 & 85 & 96 & 60 \\
\hline
\end{tabular}

CT: computed tomography, PPV: positive predictive value, NPV: negative predictive value, CCTA: coronary CT angiography, CTP: CT perfusion, FFR: fractional flow reserve by invasive coronary angiography 
and $0.53 \mathrm{mSv}$, respectively) [27-29]. In addition, there have been recent efforts to reduce the radiation dose of CT by using low $\mathrm{kV}$, iterative reconstruction techniques, and selective acquisition of the dynamic phase. Table 1 summarizes the diagnostic accuracy of the main CTP studies [28,30-34].

\section{Non-invasive FFR $\left(\mathrm{CT}_{\mathrm{FFR}}\right)$}

FFR, defined as the pressure distal to coronary stenosis relative to the pressure proximal to stenosis, has been widely used to localize ischemic lesions on ICA, and to determine the appropriate revascularization treatment [4]. It is calculated by computational fluid dynamic modeling after semiautomated segmentation of the coronary tree and left ventricular mass. $\mathrm{CT}_{\mathrm{FrR}}$ can be modeled for conditions of adenosine-induced hyperemia without adenosine infusion or additional imaging. However, it is computationally complex and time-consuming requiring sever- al hours of analysis [35]. Table 2 summarizes the diagnostic accuracy of the main $\mathrm{CT}_{\mathrm{FFR}}$ studies [4,36-39].

\section{TAG}

TAG is determined by the change (measuring the reduction in $\mathrm{HU}$ ) in the contrast opacification along coronary arteries per $10 \mathrm{~mm}$ length of the coronary artery (unit: $\mathrm{HU} / 10 \mathrm{~mm}$ ), and is calculated from the linear regression coefficient between CT attenuation and distance from the ostium. If there is significant stenosis, the slope of the graph obtained from the TAG will show a downward trend because the contrast attenuation in the distal artery will fall beyond the point of stenosis [27,35,40]. Table 3 summarizes the per-vessel diagnostic accuracy of TAG, CCTA, and $\mathrm{CT}_{\mathrm{FFR}}$ compared with invasive $\mathrm{FFR}$ as a reference standard [39-42].

Table 2. Diagnostic accuracy of $\mathrm{CT}_{\mathrm{FFR}}$

\begin{tabular}{|c|c|c|c|c|c|c|c|c|c|c|}
\hline \multirow[b]{2}{*}{ Study } & \multirow{2}{*}{$\begin{array}{c}\text { Number of } \\
\text { patients/vessels }\end{array}$} & \multirow{2}{*}{$\begin{array}{c}\text { CT } \\
\text { technique }\end{array}$} & \multicolumn{4}{|c|}{ Patient-based } & \multicolumn{4}{|c|}{ Vessel-based } \\
\hline & & & $\begin{array}{c}\text { Sensitivity } \\
(\%)\end{array}$ & $\begin{array}{c}\text { Specificity } \\
(\%)\end{array}$ & $\begin{array}{l}\text { PPV } \\
(\%)\end{array}$ & $\begin{array}{c}\text { NPV } \\
(\%)\end{array}$ & $\begin{array}{c}\text { Sensitivity } \\
(\%)\end{array}$ & $\begin{array}{c}\text { Specificity } \\
(\%)\end{array}$ & $\begin{array}{r}\text { PPV } \\
(\%)\end{array}$ & $\begin{array}{l}\text { NPV } \\
(\%)\end{array}$ \\
\hline \multirow[t]{2}{*}{ DISCOVER-FLOW [4] } & $103 / 159$ & CCTA & 94 & 25 & 58 & 80 & 91 & 40 & 47 & 89 \\
\hline & & $\mathrm{CT}_{\mathrm{FFR}}$ & 93 & 82 & 85 & 91 & 88 & 82 & 74 & 92 \\
\hline \multirow[t]{2}{*}{ DeFACTO [36] } & $252 / 615$ & CCTA & 84 & 42 & 61 & 72 & - & - & - & - \\
\hline & & $\mathrm{CT}_{\mathrm{FFR}}$ & 90 & 54 & 67 & 84 & 83 & 78 & - & - \\
\hline \multirow[t]{2}{*}{ NXT [37] } & $254 / 484$ & CCTA & 94 & 34 & 40 & 92 & 83 & 60 & 33 & 92 \\
\hline & & $\mathrm{CT}_{\mathrm{FFR}}$ & 86 & 79 & 65 & 93 & 84 & 86 & 67 & 95 \\
\hline \multirow[t]{2}{*}{ Renker et al. [38] } & $53 / 67$ & CCTA & 94 & 32 & 38 & 92 & 90 & 34 & 37 & 89 \\
\hline & & $\mathrm{CT}_{\mathrm{FFR}}$ & 94 & 84 & 71 & 97 & 85 & 85 & 71 & 93 \\
\hline \multirow[t]{2}{*}{ Yoon et al. [39] } & $53 / 82$ & CCTA & - & - & - & - & 72 & 68 & 59 & 79 \\
\hline & & $\mathrm{CT}_{\mathrm{FFR}}$ & - & - & - & - & 81 & 94 & 90 & 89 \\
\hline
\end{tabular}

CT: computed tomography, PPV: positive predictive value, NPV: negative predictive value, CCTA: coronary CT angiography, CT $\mathrm{FFR}_{\mathrm{C}} \mathrm{CT}_{\mathrm{-de}}$ rived fractional flow reserve

Table 3. Per-vessel diagnostic accuracy of TAG, CCTA, and $\mathrm{CT}_{\mathrm{FFR}}$

\begin{tabular}{|c|c|c|c|c|c|c|c|c|}
\hline Study & $\begin{array}{c}\text { Number of } \\
\text { patients/vessels }\end{array}$ & $\begin{array}{c}\text { CT machine } \\
\text { detector/slice no. }\end{array}$ & CT technique & $\begin{array}{l}\text { Reference } \\
\text { standard }\end{array}$ & $\begin{array}{c}\text { Sensitivity } \\
(\%)\end{array}$ & $\begin{array}{l}\text { Specificity } \\
(\%)\end{array}$ & $\begin{array}{l}\text { PPV } \\
(\%)\end{array}$ & $\begin{array}{c}\text { NPV } \\
(\%)\end{array}$ \\
\hline \multirow[t]{2}{*}{ Wong et al. [41] } & $54 / 78$ & $320 / 320$ & TAG & $\mathrm{FFR} \leq 0.80$ & 77 & 74 & 67 & 86 \\
\hline & & & CCTA $>50 \%$ & & 94 & 66 & 64 & 94 \\
\hline \multirow[t]{3}{*}{ Choi et al. [42] } & $63 / 97$ & $64 / 64$ & TAG & FFR $\leq 0.80$ & 48 & 91 & 79 & 71 \\
\hline & & & TAG/CCO & & 65 & 61 & 54 & 71 \\
\hline & & & CCTA $>50 \%$ & & 95 & 53 & 58 & 91 \\
\hline \multirow[t]{3}{*}{ Yoon et al. [39] } & $53 / 82$ & $64 / 64$ & TAG & $\mathrm{FFR} \leq 0.80$ & 38 & 88 & 67 & 69 \\
\hline & & & CCTA $>70 \%$ & & 72 & 68 & 59 & 79 \\
\hline & & & $\mathrm{CT}_{\mathrm{FFR}}$ & & 81 & 94 & 90 & 89 \\
\hline \multirow[t]{3}{*}{ Choi et al. [40] } & $85 / 253$ & $128 / 256$ & TAG & $\mathrm{FFR} \leq 0.80$ & 69 & 44 & 27 & 83 \\
\hline & & & TAG/CCO & & 63 & 54 & 29 & 91 \\
\hline & & & CCTA $>50 \%$ & & 95 & 75 & 54 & 98 \\
\hline
\end{tabular}

CT: computed tomography, PPV: positive predictive value, NPV: negative predictive value, TAG: transluminal attenuation gradient, TAG/CCO: transluminal attenuation gradient/corrected contrast opacification, CCTA: coronary CT angiography, FFR: fractional flow reserve, CT $\mathrm{FFR}$ : CTderived fractional flow reserve 


\section{STEP 2. GUIDING THE REVASCULARIZATION PROCEDURE ONCE THE REVASCULARIZATION IS DETERMINED}

Although CCTA can provide information about significant coronary artery stenosis and has prognostic value, only a few studies have investigated the role of CCTA in guiding patient treatment, such as determining the need for revascularization or the appropriate revascularization procedure [e.g., percutaneous coronary intervention (PCI) vs. CABG surgery]. Traditionally, CABG has been recommended in patients with multivessel disease or high- and medium-risk patients as compared to medical treatment [43]. Since the introduction of the drug eluting stent, the restenosis rate has been significantly reduced compared to the rate using the bare metal stent, thus leading to the increased confidence of interventional cardiologists for treating multivessel diseases, which had previously been the scope of thoracic surgeons. Table 4 summarize the results of the major studies comparing PCI with CABG in patients with multivessel disease [44-49].

Currently, the Synergy between PCI with TAXUS and Cardiac Surgery (SYNTAX) score has been introduced as an angiographic score to assess the extent and complexity of CAD and is known to be an independent predictor of major adverse cardiac events in populations with a varying extent of CAD [48]. The SYNTAX score demonstrates the extent and complexity of the lesion, therefore 2011 American College of Cardiology Foundation/American Heart Association (ACCF/AHA) guidelines for CABG surgery mentioned that the SYNTAX score is a reasonable surrogate for the extent of CAD [50]. Recently, CCTA has been reported to be a feasible and reproducible modality for noninvasive estimation of the SYNTAX score and Suh et al. [51] reported that combining a CT-based SYNTAX score can be a highly specific method for selecting CABG surgery candidates.

\section{STEP 3. ROLE OF CCTA FOR CHRONIC TOTAL OCCLUSION}

CTO was defined as occlusion of a native coronary artery estimated from the clinical event to be present for at least three months or more, with no luminal continuity and a thrombolysis in myocardial infarction (TIMI) of 0 or 1 anterograde flow on angiography [52]. Because CTO territories are ischemic despite the presence of collateral channels, restoration of normal blood flow has improved symptoms and ventricular function. However, CTO lesions are the most challenging because of the high rate of complications and long-term adverse events, mostly due to failure in tracking or navigation of hardware through the occluded CTO segment, prolonged exposure to radiation, and the high dose of contrast agent used. Therefore, proper patient selection is of utmost importance. In this regard, CCTA helps to better define the morphological features of the occluded CTO segment such as the actual length of the occluded segment and any calcifications or tortuosity in its course, which are established predictors of success [53] (Fig. 3). As compared to the JCTO score (a multicenter CTO registry in Japan), which was developed using various angiographic variables, the Computed Tomography Registry of Chronic Total Occlusion Revascular-

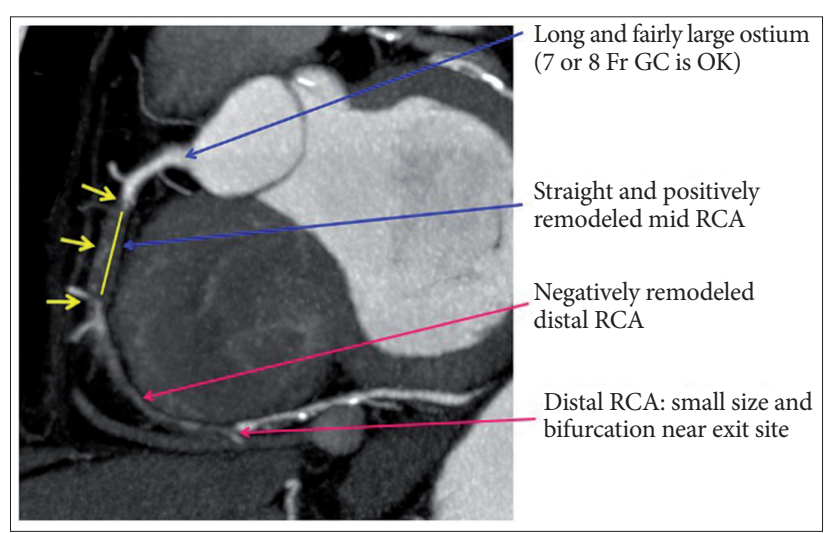

Fig. 3. Role of coronary CT angiography in patients with chronic total occlusion. GC: guiding catheter, CT: computed tomography, RCA: right coronary artery.

Table 4. Comparison studies between CABG and percutaneous coronary intervention in patients with multi-vessel diseases

\begin{tabular}{|c|c|c|c|c|c|}
\hline \multirow{2}{*}{ Study } & \multirow{2}{*}{ Patients (n) } & \multirow{2}{*}{ Stent type } & \multicolumn{2}{|c|}{ Event [CABG vs. Stent (p-value)] } & \multirow{2}{*}{$\begin{array}{c}\text { Follow-up } \\
\text { duration (yrs) }\end{array}$} \\
\hline & & & MACE & Death & \\
\hline SOS [44] & 988 & BMS & - & $6.8 \%$ vs. $10.9 \%(\mathrm{p}=0.02)$ & 6 \\
\hline AWESOME [45] & 142 & BMS & - & $21.0 \%$ vs. $20.0 \%(\mathrm{p}=0.46)$ & 3 \\
\hline MASS II [46] & 611 & BMS & - & $25.1 \%$ vs. $24.1 \%(\mathrm{p}=0.09)$ & 10 \\
\hline ARTS II [47] & 1205 & BMS & $21.8 \%$ vs. $41.7 \%(\mathrm{p}<0.01)$ & $7.6 \%$ vs. $8.0 \%(\mathrm{p}=0.83)$ & 5 \\
\hline SYNTAX [48] & 1800 & DES & $26.9 \%$ vs. $37.3 \%(\mathrm{p}<0.001)$ & $11.4 \%$ vs. $13.9 \%(\mathrm{p}=0.10)$ & 5 \\
\hline CARDia [49] & 510 & DES & $11.3 \%$ vs. $19.3 \%(\mathrm{p}=0.02)$ & $3.2 \%$ vs. $3.2 \%(p=0.97)$ & 1 \\
\hline FREEDOM [50] & 1900 & DES & $11.8 \%$ vs. $16.8 \%(\mathrm{p}<0.01)$ & $10.9 \%$ vs. $16.3 \%(\mathrm{p}=0.05)$ & 5 \\
\hline
\end{tabular}

CABG: coronary artery bypass graft, BMS: bare metal stent, DES: drug eluting stent, MACE: major adverse cardiovascular and cerebrovascular events 
ization (CT-RECTOR) score which is made based on CT variables has a higher success rate because CCTA can demonstrate multiple occlusions or severe calcifications [54,55] (Table 5).

\section{STEP 4. ROLE OF CCTA FOR FOLLOW-UP OF PATIENTS WITH PREVIOUS REVASCULARIZATION}

\section{CABG}

CCTA can be used to assess the patency of CABG with high diagnostic accuracy compared to the assessment of native coronaries, because CABG have larger vessel diameters, are less movable, and have a lower propensity to develop calcified plaques compared with native coronaries [56] (Fig. 4). In meta-analysis, CCTA demonstrates high diagnostic accuracy with a sensitivity of $97.6 \%$, specificity of $96.7 \%$, and NPV of $98.9 \%$ [57]. CCTA can also be helpful for the evaluation of the internal mammary artery in relation to the sternum in patients considering redoCABG (repeat coronary artery bypass grafting).

Despite the technical developments of the CT technique, non-

Table 5. Angiographic and CT predictors of failure for percutaneous coronary intervention on CTO

\begin{tabular}{lll}
\hline & Angiographic predictors (J-CTO score) & CT predictors (CT-RECTOR score) \\
\hline Imaging (point) & Occlusion length $\geq 2 \mathrm{~cm} \mathrm{(1)}$ & Multiple occlusion (1) \\
& Blunt stump (1) & Blunt stump (1) \\
& Any calcification (1) & Severe calcification* $(1)$ \\
& Bending $\geq 45$ degrees (1) & Bending $\geq 45$ degrees $(1)$ \\
Clinical (point) & Re-try lesion (1) & Second attempt $(1)$ \\
& & Duration of CCTA $>1$ yr $(1)$ \\
Category of difficulty (total point) & Easy (0) & Easy (0) \\
& Intermediate $(1)$ & Intermediate $(1)$ \\
& Difficult $(2)$ & Difficult $(2)$ \\
& Very difficult $(\geq 3)$ & Very difficult $(\geq 3)$
\end{tabular}

*severe calcification means presence of any calcium involving $\geq 50 \%$ of the vessel cross-sectional area at the entry or exit site or within the occlusion route. CT: computed tomography, CTO: chronic total occlusion, CCTA: coronary CT angiography, J-CTO: multicenter CTO registry in Japan, CT-RECTOR: Computed Tomography Registry of Chronic Total Occlusion Revascularization
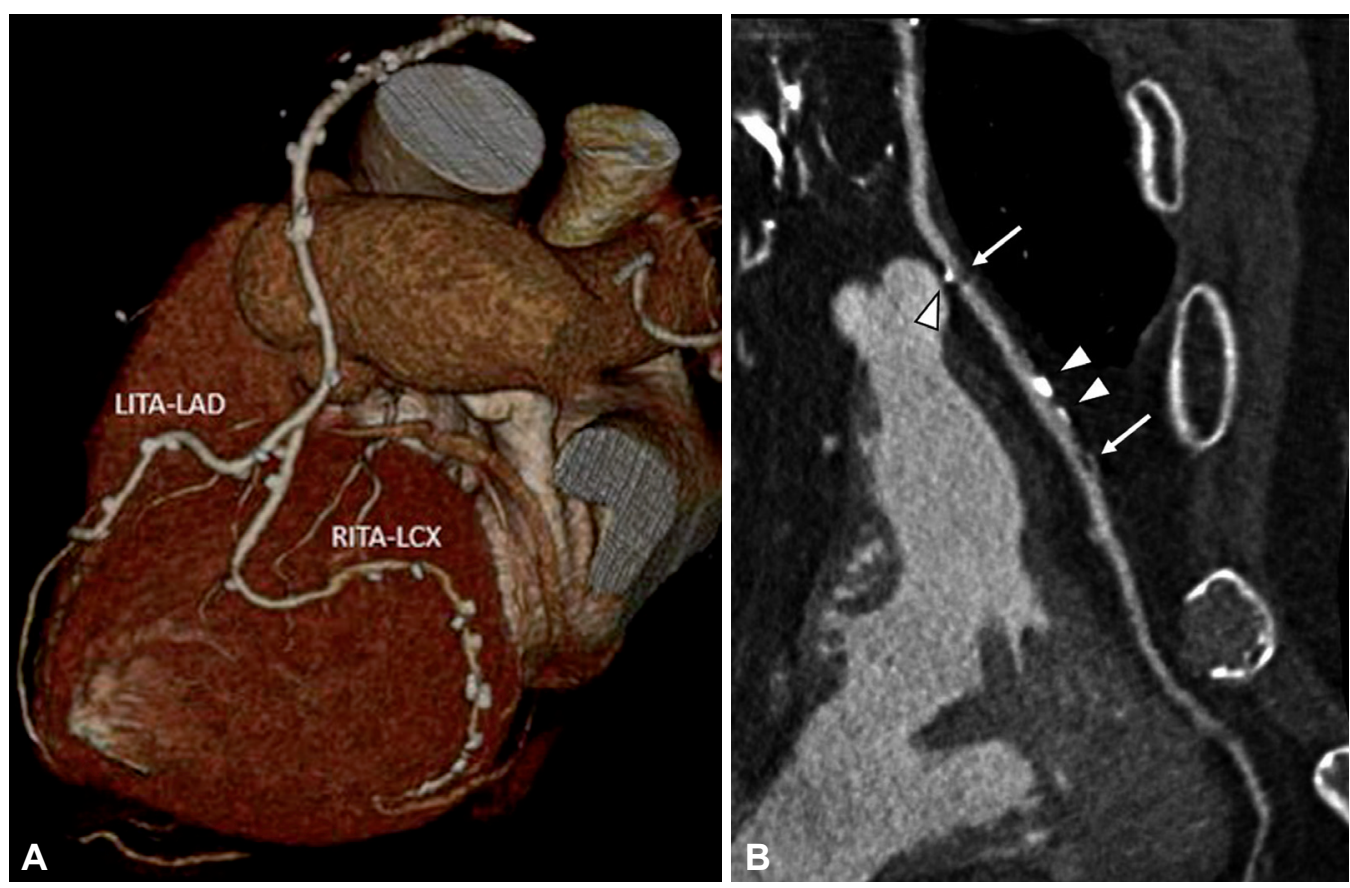

Fig. 4. Coronary artery bypass graft in a 48-year-old male. (A) Volume rendered CT image well demonstrates two grafts (LITA-LAD and RITA-LCX) with Y-shaped anastomosis. Notes: LITA-LAD indicates bypass between the left internal thoracic artery and distal left anterior descending artery, and RITA-LCX indicates a graft between the right internal thoracic artery and left circumflex artery. (B) Curved multiplanar reconstruction image of the LITA-LAD graft shows multiple insignificant stenoses (arrows). Because multiple surgical clips (arrowheads) sometimes hampered the luminal stenosis or were confused as a calcified plaque, careful evaluation of the graft lumen is necessary. CT: computed tomography. 
evaluable grafts have remained due to artifacts from surgical metal clips, mild stair-step motion artifacts, flow competition of the arterial graft, and severe calcifications of the native coronary vessels $[58,59]$. Another limitation of CT for evaluation of $\mathrm{CABG}$ is the issue of radiation exposure because the scan range should be extended for evaluation of CABG beyond the native coronary arteries. However, introduction of various radiation reduction techniques such as prospective ECG gating, iterative reconstruction, or high pitch techniques can reduce radiation exposure while maintaining image quality and high diagnostic accuracy $[60,61]$.

\section{In-stent restenosis}

As compared to $\mathrm{CABG}$, the diagnostic accuracy in patients who received stents varies because the accuracy is affected by the diameter of the stent and size of the stent struts. According to recent meta-analysis studies, the diagnostic accuracy of CCTA for stent patency is as high as $90 \%$, with sensitivity of $89.7-$ $90 \%$, specificity of $91-92.2 \%$, PPV of $72.5 \%$, and NPV of $97.4 \%$ [62] (Fig. 5). Overall, diagnostic accuracy is significantly high- er in stents with larger vessel diameters. CCTA demonstrated that the sensitivity, specificity, PPV, and NPV were $67,78,57$, and $85 \%$, respectively, for stents $<3.0 \mathrm{~mm}$ in diameter, whereas for stents $\geq 3.0 \mathrm{~mm}$ in diameter, the sensitivity, specificity, PPV, and NPV were increased at $89,100,100$, and $97 \%$, respectively [63]. Moreover, the diagnostic performance of CCTA has been found to be superior in stents with thinner struts $(<100 \mu \mathrm{m})$ compared to stents with thicker struts [63]. Due to limitations in CT technology, CCTA is not yet recommended for stents $<3.0 \mathrm{~mm}$ in diameter [8]. However, the recent introduction of high spatial resolution CT $(0.23 \mathrm{~mm})$ and a calcium subtraction algorithm using dual energy CT may improve the accuracy of the evaluation of in-stent restenosis $[64,65]$.

\section{CONCLUSION}

CCTA is now widely used as a reliable non-invasive imaging test for CAD assessment that can be performed quickly and has high diagnostic accuracy. The quantification of plaques which cannot be observed in ICA has made it possible to predict prog-

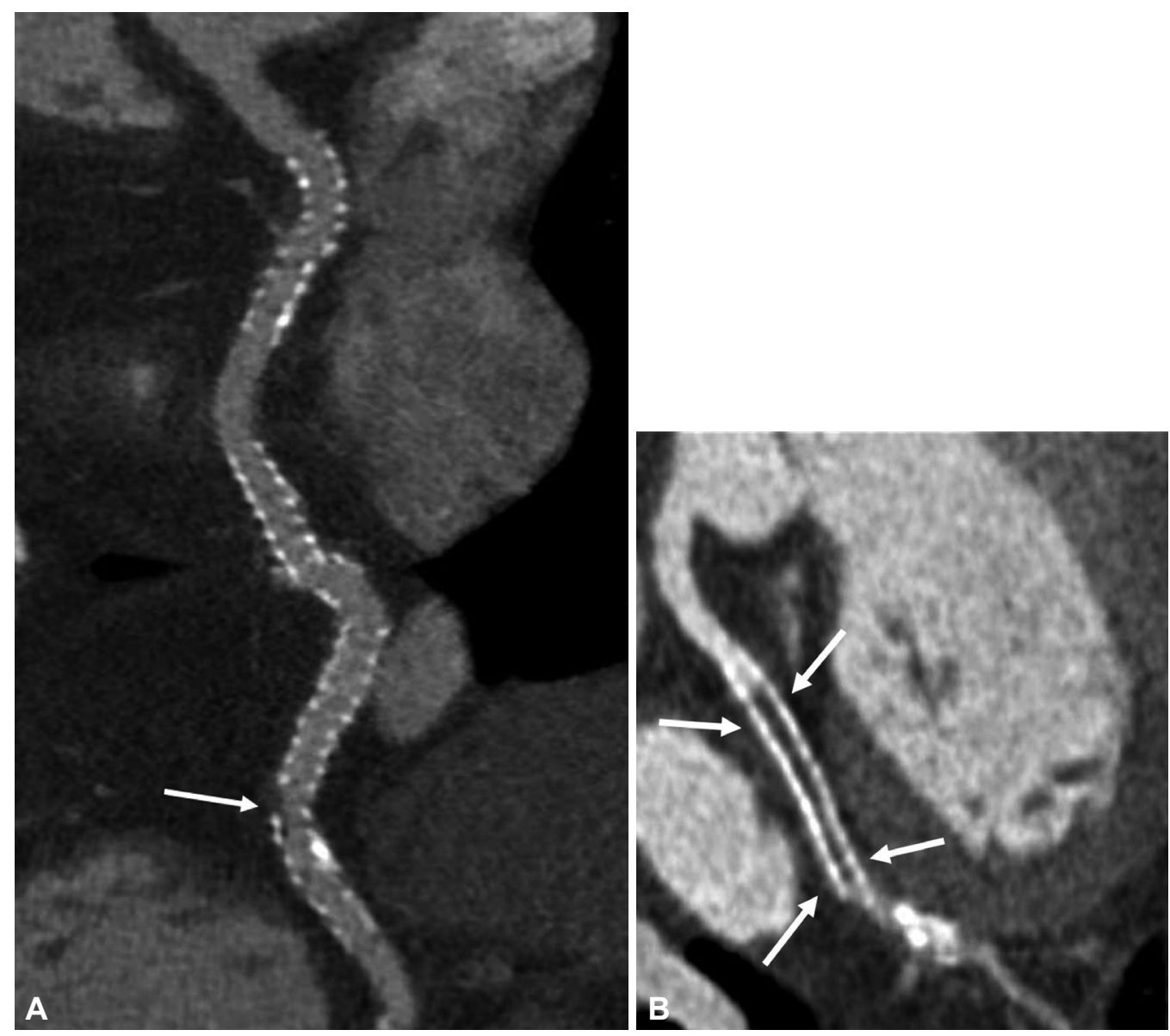

Fig. 5. Stent evaluation with coronary computed tomography angiography. (A) Curved MPR of the RCA in a 53-year-old male shows multiple stents from the proximal to distal RCA. There is no significant in-stent restenosis, although there is minimal in-stent restenosis (arrow). (B) Curved MPR of the left circumflex artery in a 62-year-old female with acute chest pain shows total occlusion within the stent (arrows), suggesting a thrombotic occlusion. RCA: right coronary artery, MPR: multiplanar reconstruction. 
nosis, and the recently introduced various CT-based myocardial ischemic burden assessments can help to guide the treatment plan.

Although spatial resolution of CT is not satisfactory and radiation exposure is still considered a problem, the development of technology is expected to increasingly overcome these limitations, thus CCTA will play an important role not only in diagnosis but also in the treatment strategy for CAD management.

\section{Conflicts of Interest}

The authors declare that they have no conflict of interest.

\section{Acknowledgments}

This study has received funding from the National Research Foundation (NRF) grant funded by the Korea government (MEST) (NRF-2015R1D1A1 A01059717).

\section{REFERENCES}

1. Hamon M, Biondi-Zoccai GG, Malagutti P, Agostoni P, Morello R, Valgimigli $\mathrm{M}$, et al. Diagnostic performance of multislice spiral computed tomography of coronary arteries as compared with conventional invasive coronary angiography: a meta-analysis. J Am Coll Cardiol 2006;48:18961910.

2. Puchner SB, Liu T, Mayrhofer T, Truong QA, Lee H, Fleg JL, et al. Highrisk plaque detected on coronary $\mathrm{CT}$ angiography predicts acute coronary syndromes independent of significant stenosis in acute chest pain: results from the ROMICAT-II trial. J Am Coll Cardiol 2014;64:684-692.

3. Ko BS, Cameron JD, Leung M, Meredith IT, Leong DP, Antonis PR, et al. Combined CT coronary angiography and stress myocardial perfusion imaging for hemodynamically significant stenoses in patients with suspected coronary artery disease: a comparison with fractional flow reserve. JACC Cardiovasc Imaging 2012;5:1097-1111.

4. Koo BK, Erglis A, Doh JH, Daniels DV, Jegere S, Kim HS, et al. Diagnosis of ischemia-causing coronary stenoses by noninvasive fractional flow reserve computed from coronary computed tomographic angiograms. Results from the prospective multicenter DISCOVER-FLOW (diagnosis of ischemia-causing stenoses obtained via noninvasive fractional flow reserve) study. J Am Coll Cardiol 2011;58:1989-1997.

5. Choi JH, Min JK, Labounty TM, Lin FY, Mendoza DD, Shin DH, et al. Intracoronary transluminal attenuation gradient in coronary $\mathrm{CT}$ angiography for determining coronary artery stenosis. JACC Cardiovasc Imaging 2011;4:1149-1157.

6. Papadopoulou SL, Girasis C, Dharampal A, Farooq V, Onuma Y, Rossi A, et al. CT-SYNTAX score: a feasibility and reproducibility study. JACC Cardiovasc Imaging 2013;6:413-415.

7. García-García HM, van Mieghem CA, Gonzalo N, Meijboom WB, Weustink AC, Onuma Y, et al. Computed tomography in total coronary occlusions (CTTO registry): radiation exposure and predictors of successful percutaneous intervention. EuroIntervention 2009;4:607-616.

8. Taylor AJ, Cerqueira M, Hodgson JM, Mark D, Min J, O'Gara P, et al. ACCF/SCCT/ACR/AHA/ASE/ASNC/NASCI/SCAI/SCMR 2010 appropriate use criteria for cardiac computed tomography. A report of the American College of Cardiology Foundation Appropriate Use Criteria Task Force, the Society of Cardiovascular Computed Tomography, the American College of Radiology, the American Heart Association, the American Society of Echocardiography, the American Society of Nuclear Cardiology, the North American Society for Cardiovascular Imaging, the Society for Cardiovascular Angiography and Interventions, and the Society for Cardiovascular Magnetic Resonance. J Am Coll Cardiol 2010;56: 1864-1894.

9. Achenbach S, Daniel WG. Computed tomography of the coronary arteries: more than meets the (angiographic) eye. J Am Coll Cardiol 2005;46:
155-157.

10. Pontone G, Bertella E, Mushtaq S, Loguercio M, Cortinovis S, Baggiano A, et al. Coronary artery disease: diagnostic accuracy of CT coronary angiography--a comparison of high and standard spatial resolution scanning. Radiology 2014;271:688-694.

11. Westwood ME, Raatz HD, Misso K, Burgers L, Redekop K, Lhachimi SK, et al. Systematic review of the accuracy of dual-source cardiac CT for detection of arterial stenosis in difficult to image patient groups. Radiology 2013;267:387-395

12. Meijboom WB, Meijs MF, Schuijf JD, Cramer MJ, Mollet NR, van Mieghem CA, et al. Diagnostic accuracy of 64-slice computed tomography coronary angiography: a prospective, multicenter, multivendor study. J Am Coll Cardiol 2008;52:2135-2144.

13. Hulten EA, Carbonaro S, Petrillo SP, Mitchell JD, Villines TC. Prognostic value of cardiac computed tomography angiography: a systematic review and meta-analysis. J Am Coll Cardiol 2011;57:1237-1247.

14. Arbab-Zadeh A, Miller JM, Rochitte CE, Dewey M, Niinuma H, Gottlieb I, et al. Diagnostic accuracy of computed tomography coronary angiography according to pre-test probability of coronary artery disease and severity of coronary arterial calcification. The CORE-64 (coronary artery evaluation using 64-row multidetector computed tomography angiography) International Multicenter Study. J Am Coll Cardiol 2012;59:379-387.

15. Motoyama S, Sarai M, Harigaya H, Anno H, Inoue K, Hara T, et al. Computed tomographic angiography characteristics of atherosclerotic plaques subsequently resulting in acute coronary syndrome. J Am Coll Cardiol 2009;54:49-57.

16. Maurovich-Horvat P, Hoffmann U, Vorpahl M, Nakano M, Virmani R, Alkadhi $\mathrm{H}$. The napkin-ring sign: CT signature of high-risk coronary plaques? JACC Cardiovasc Imaging 2010;3:440-444.

17. Virmani R, Burke AP, Farb A, Kolodgie FD. Pathology of the vulnerable plaque. J Am Coll Cardiol 2006;47(8 Suppl):C13-C18.

18. Leber AW, Knez A, Becker A, Becker C, von Ziegler F, Nikolaou K, et al. Accuracy of multidetector spiral computed tomography in identifying and differentiating the composition of coronary atherosclerotic plaques: a comparative study with intracoronary ultrasound. J Am Coll Cardiol 2004; 43:1241-1247.

19. Otsuka K, Fukuda S, Tanaka A, Nakanishi K, Taguchi H, Yoshikawa J, et al. Napkin-ring sign on coronary CT angiography for the prediction of acute coronary syndrome. JACC Cardiovasc Imaging 2013;6:448-457.

20. Schlett CL, Maurovich-Horvat P, Ferencik M, Alkadhi H, Stolzmann P, Scheffel $\mathrm{H}$, et al. Histogram analysis of lipid-core plaques in coronary computed tomographic angiography: ex vivo validation against histology. Invest Radiol 2013;48:646-653.

21. Glagov S, Weisenberg E, Zarins CK, Stankunavicius R, Kolettis GJ. Compensatory enlargement of human atherosclerotic coronary arteries. $\mathrm{N}$ Engl J Med 1987;316:1371-1375.

22. Narula J, Nakano M, Virmani R, Kolodgie FD, Petersen R, Newcomb R, et al. Histopathologic characteristics of atherosclerotic coronary disease and implications of the findings for the invasive and noninvasive detection of vulnerable plaques. J Am Coll Cardiol 2013;61:1041-1051.

23. Kashiwagi M, Tanaka A, Kitabata H, Tsujioka H, Kataiwa H, Komukai K, et al. Feasibility of noninvasive assessment of thin-cap fibroatheroma by multidetector computed tomography. JACC Cardiovasc Imaging 2009; 2:1412-1419.

24. van Velzen JE, de Graaf FR, de Graaf MA, Schuijf JD, Kroft LJ, de Roos A, et al. Comprehensive assessment of spotty calcifications on computed tomography angiography: comparison to plaque characteristics on intravascular ultrasound with radiofrequency backscatter analysis. J Nucl Cardiol 2011;18:893-903.

25. Huang H, Virmani R, Younis H, Burke AP, Kamm RD, Lee RT. The impact of calcification on the biomechanical stability of atherosclerotic plaques. Circulation 2001;103:1051-1056.

26. Varga-Szemes A, Meinel FG, De Cecco CN, Fuller SR, Bayer RR 2nd, Schoepf UJ. CT myocardial perfusion imaging. AJR Am J Roentgenol 2015;204:487-497. 
27. Koo HJ, Yang DH, Kim YH, Kang JW, Kang SJ, Kweon J, et al. CT-based myocardial ischemia evaluation: quantitative angiography, transluminal attenuation gradient, myocardial perfusion, and CT-derived fractional flow reserve. Int J Cardiovasc Imaging 2016;32 Suppl 1:1-19.

28. Yang DH, Kim YH, Roh JH, Kang JW, Han D, Jung J, et al. Stress myocardial perfusion CT in patients suspected of having coronary artery disease: visual and quantitative analysis-validation by using fractional flow reserve. Radiology 2015;276:715-723.

29. Feuchtner G, Goetti R, Plass A, Wieser M, Scheffel H, Wyss C, et al. Adenosine stress high-pitch 128-slice dual-source myocardial computed tomography perfusion for imaging of reversible myocardial ischemia: comparison with magnetic resonance imaging. Circ Cardiovasc Imaging 2011; 4:540-549.

30. Ko BS, Cameron JD, Meredith IT, Leung M, Antonis PR, Nasis A, et al. Computed tomography stress myocardial perfusion imaging in patients considered for revascularization: a comparison with fractional flow reserve. Eur Heart J 2012;33:67-77.

31. Bettencourt N, Chiribiri A, Schuster A, Ferreira N, Sampaio F, Pires-Morais $\mathrm{G}$, et al. Direct comparison of cardiac magnetic resonance and multidetector computed tomography stress-rest perfusion imaging for detection of coronary artery disease. J Am Coll Cardiol 2013;61:1099-1107.

32. Wong DT, Ko BS, Cameron JD, Leong DP, Leung MC, Malaiapan Y, et al. Comparison of diagnostic accuracy of combined assessment using adenosine stress computed tomography perfusion+computed tomography angiography with transluminal attenuation gradient+computed tomography angiography against invasive fractional flow reserve. J Am Coll Cardiol 2014;63:1904-1912.

33. Choo KS, Hwangbo L, Kim JH, Park YH, Kim JS, Kim J, et al. Adenosinestress low-dose single-scan CT myocardial perfusion imaging using a 128-slice dual-source CT: a comparison with fractional flow reserve. Acta Radiol 2013;54:389-395.

34. Greif M, von Ziegler F, Bamberg F, Tittus J, Schwarz F, D'Anastasi M, et al. CT stress perfusion imaging for detection of haemodynamically relevant coronary stenosis as defined by FFR. Heart 2013;99:1004-1011.

35. Hecht HS, Narula J, Fearon WF. Fractional flow reserve and coronary computed tomographic angiography: a review and critical analysis. Circ Res 2016;119:300-316.

36. Min JK, Leipsic J, Pencina MJ, Berman DS, Koo BK, van Mieghem C, et al. Diagnostic accuracy of fractional flow reserve from anatomic CT angiography. JAMA 2012;308:1237-1245.

37. Nørgaard BL, Leipsic J, Gaur S, Seneviratne S, Ko BS, Ito H, et al. Diagnostic performance of noninvasive fractional flow reserve derived from coronary computed tomography angiography in suspected coronary artery disease: the NXT trial (Analysis of Coronary Blood Flow Using CT Angiography: Next Steps). J Am Coll Cardiol 2014;63:1145-1155.

38. Renker M, Schoepf UJ, Wang R, Meinel FG, Rier JD, Bayer RR 2nd, et al. Comparison of diagnostic value of a novel noninvasive coronary computed tomography angiography method versus standard coronary angiography for assessing fractional flow reserve. Am J Cardiol 2014;114:13031308.

39. Yoon YE, Choi JH, Kim JH, Park KW, Doh JH, Kim YJ, et al. Noninvasive diagnosis of ischemia-causing coronary stenosis using CT angiography: diagnostic value of transluminal attenuation gradient and fractional flow reserve computed from coronary CT angiography compared to invasively measured fractional flow reserve. JACC Cardiovasc Imaging 2012;5: 1088-1096.

40. Choi JH, Kim EK, Kim SM, Song YB, Hahn JY, Choi SH, et al. Noninvasive evaluation of coronary collateral arterial flow by coronary computed tomographic angiography. Circ Cardiovasc Imaging 2014;7:482-490.

41. Wong DT, Ko BS, Cameron JD, Nerlekar N, Leung MC, Malaiapan Y, et al. Transluminal attenuation gradient in coronary computed tomography angiography is a novel noninvasive approach to the identification of functionally significant coronary artery stenosis: a comparison with fractional flow reserve. J Am Coll Cardiol 2013;61:1271-1279.

42. Choi JH, Koo BK, Yoon YE, Min JK, Song YB, Hahn JY, et al. Diagnostic performance of intracoronary gradient-based methods by coronary computed tomography angiography for the evaluation of physiologically significant coronary artery stenoses: a validation study with fractional flow reserve. Eur Heart J Cardiovasc Imaging 2012;13:1001-1007.

43. Yusuf S, Zucker D, Peduzzi P, Fisher LD, Takaro T, Kennedy JW, et al. Effect of coronary artery bypass graft surgery on survival: overview of 10year results from randomised trials by the Coronary Artery Bypass Graft Surgery Trialists Collaboration. Lancet 1994;344:563-570.

44. Booth J, Clayton T, Pepper J, Nugara F, Flather M, Sigwart U, et al. Randomized, controlled trial of coronary artery bypass surgery versus percutaneous coronary intervention in patients with multivessel coronary artery disease: six-year follow-up from the Stent or Surgery Trial (SoS). Circulation 2008;118:381-388.

45. Morrison DA, Sethi G, Sacks J, Henderson W, Grover F, Sedlis S, et al. Percutaneous coronary intervention versus coronary artery bypass graft surgery for patients with medically refractory myocardial ischemia and risk factors for adverse outcomes with bypass: a multicenter, randomized trial. Investigators of the Department of Veterans Affairs Cooperative Study \#385, the Angina With Extremely Serious Operative Mortality Evaluation (AWESOME). J Am Coll Cardiol 2001;38:143-149.

46. Hueb W, Lopes N, Gersh BJ, Soares PR, Ribeiro EE, Pereira AC, et al. Tenyear follow-up survival of the medicine, angioplasty, or surgery study (MASS II): a randomized controlled clinical trial of 3 therapeutic strategies for multivessel coronary artery disease. Circulation 2010;122:949957.

47. Serruys PW, Ong AT, Morice MC, De Bruyne B, Colombo A, Macaya C, et al. Arterial revascularisation therapies study part II-sirolimus-eluting stents for the treatment of patients with multivessel de novo coronary artery lesions. EuroIntervention 2005;1:147-156.

48. Mohr FW, Morice MC, Kappetein AP, Feldman TE, Ståhle E, Colombo A, et al. Coronary artery bypass graft surgery versus percutaneous coronary intervention in patients with three-vessel disease and left main coronary disease: 5-year follow-up of the randomised, clinical SYNTAX trial. Lancet 2013;381:629-638.

49. Kapur A, Hall RJ, Malik IS, Qureshi AC, Butts J, de Belder M, et al. Randomized comparison of percutaneous coronary intervention with coronary artery bypass grafting in diabetic patients. 1-year results of the CARDia (Coronary Artery Revascularization in Diabetes) trial. J Am Coll Cardiol 2010;55:432-440.

50. Hillis LD, Smith PK, Anderson JL, Bittl JA, Bridges CR, Byrne JG, et al. 2011 ACCF/AHA Guideline for Coronary Artery Bypass Graft Surgery: executive summary: a report of the American College of Cardiology Foundation/American Heart Association Task Force on Practice Guidelines. Circulation 2011;124:2610-2642.

51. Suh YJ, Hong YJ, Lee HJ, Hur J, Kim YJ, Hong SR, et al. Accuracy of CT for selecting candidates for coronary artery bypass graft surgery: combination with the SYNTAX score. Radiology 2015;276:390-399.

52. Sianos G, Werner GS, Galassi AR, Papafaklis MI, Escaned J, HildickSmith D, et al. Recanalisation of chronic total coronary occlusions: 2012 consensus document from the EuroCTO club. EuroIntervention 2012;8: 139-145.

53. Choi JH, Song YB, Hahn JY, Choi SH, Gwon HC, Cho JR, et al. Three-dimensional quantitative volumetry of chronic total occlusion plaque using coronary multidetector computed tomography. Circ J 2011;75:366-375.

54. Morino Y, Abe M, Morimoto T, Kimura T, Hayashi Y, Muramatsu T, et al. Predicting successful guidewire crossing through chronic total occlusion of native coronary lesions within 30 minutes: the J-CTO (Multicenter CTO Registry in Japan) score as a difficulty grading and time assessment tool. JACC Cardiovasc Interv 2011;4:213-221.

55. Opolski MP, Achenbach S, Schuhbäck A, Rolf A, Möllmann H, Nef H, et al. Coronary computed tomographic prediction rule for time-efficient guidewire crossing through chronic total occlusion: insights from the CTRECTOR multicenter registry (Computed Tomography Registry of Chronic Total Occlusion Revascularization). JACC Cardiovasc Interv 2015;8:257267. 
56. Frazier AA, Qureshi F, Read KM, Gilkeson RC, Poston RS, White CS. Coronary artery bypass grafts: assessment with multidetector $\mathrm{CT}$ in the early and late postoperative settings. Radiographics 2005;25:881-896.

57. Hamon M, Lepage O, Malagutti P, Riddell JW, Morello R, Agostini D, et al. Diagnostic performance of 16- and 64-section spiral CT for coronary artery bypass graft assessment: meta-analysis. Radiology 2008;247:679-686.

58. Meyer TS, Martinoff S, Hadamitzky M, Will A, Kastrati A, Schömig A, et al. Improved noninvasive assessment of coronary artery bypass grafts with 64-slice computed tomographic angiography in an unselected patient population. J Am Coll Cardiol 2007;49:946-950.

59. Jabara R, Chronos N, Klein L, Eisenberg S, Allen R, Bradford S, et al. Comparison of multidetector 64-slice computed tomographic angiography to coronary angiography to assess the patency of coronary artery bypass grafts. Am J Cardiol 2007;99:1529-1534.

60. Lee JH, Chun EJ, Choi SI, Vembar M, Lim C, Park KH, et al. Prospective versus retrospective ECG-gated 64-detector coronary CT angiography for evaluation of coronary artery bypass graft patency: comparison of image quality, radiation dose and diagnostic accuracy. Int J Cardiovasc Imaging 2011;27:657-667.

61. Nepveu S, Stevens LM, Chartrand-Lefebvre C. Iterative reconstruction in 256-MDCT of coronary artery bypass grafts: assessment of radiation dose reduction and image quality. AJR Am J Roentgenol 2014;202:W599.

62. Sun Z, Almutairi AM. Diagnostic accuracy of 64 multislice CT angiography in the assessment of coronary in-stent restenosis: a meta-analysis. Eur J Radiol 2010;73:266-273.

63. Andreini D, Pontone G, Mushtaq S, Bartorelli AL, Bertella E, Trabattoni $\mathrm{D}$, et al. Coronary in-stent restenosis: assessment with CT coronary angiography. Radiology 2012;265:410-417.

64. Fuchs TA, Stehli J, Fiechter M, Dougoud S, Sah BR, Gebhard C, et al. First in vivo head-to-head comparison of high-definition versus standard-definition stent imaging with 64-slice computed tomography. Int J Cardiovasc Imaging 2013;29:1409-1416.

65. Yoshioka K, Tanaka R, Muranaka K. Subtraction coronary CT angiography for calcified lesions. Cardiol Clin 2012;30:93-102. 